\title{
Opposite effects of tumor protein D (TPD) 52 and TPD54 on oral squamous cell carcinoma cells
}

\author{
KOSUKE KATO $^{1}$, YOSHIKI MUKUDAI ${ }^{1}$, HIROMI MOTOHASHI ${ }^{1}$, CHIHIRO ITO $^{1}$, \\ SHINNOSUKE KAMOSHIDA ${ }^{1}$, TOSHIKAZU SHIMANE ${ }^{1}$, SEIJI KONDO ${ }^{1,2}$ and TATSUO SHIROTA ${ }^{1}$ \\ ${ }^{1}$ Department of Oral and Maxillofacial Surgery, School of Dentistry, Showa University, Ota-ku, \\ Tokyo 145-8515; ${ }^{2}$ Department of Oral and Maxillofacial Surgery, Faculty of Medicine, \\ Fukuoka University, Jonan-ku, Fukuoka 814-0180, Japan
}

Received December 21, 2016; Accepted February 13, 2017

DOI: 10.3892/ijo.2017.3929

\begin{abstract}
The tumor protein D52 (TPD52) protein family includes TPD52, $-53,-54$ and -55 . Several reports have shown important roles for TPD52 and TPD53, and have also suggested the potential involvement of TPD54, in D52-family physiological effects. Therefore, we performed detailed expression analysis of TPD52 family proteins in oral squamous cell carcinoma (OSCC). Towards this end, TPD54-overexpressing or knocked-down cells were constructed using OSCC-derived SAS, HSC 2 and HSC 3 cells. tpd52 or tpd53 was expressed or co-expressed in these cells by transfection. The cells were then analyzed using cell viability (MTT), colony formation, migration, and invasion assays. In OSCC-xenograft experiments, the cells were transplanted into nude mice together with injection of anti-tpd siRNAs. MTT assay of cell monolayers showed little differences in growth of the transfected cells. tpd54 overexpression in SAS cells significantly decreased colony formation in an anchorage-independent manner. Additionally, knock-down of tpd54 enhanced the number of colonies formed and overexpression of tpd52 in tpd54 knock-down cells increased the size of the colonies formed. The chemotaxis assay showed that tpd54 overexpression decreased cell migration. In the OSCC-xenograft in vivo study, tpd54 overexpression slightly attenuated tumor volume in vivo, despite the fact that tumor metastasis or cell survival was not involved. Our results showed that TPD54 not only downregulated anchorage-independent growth and cell migration in vitro, but also attenuated tumor growth in vivo. Based on these results, it is considered that TPD54 might act as a negative regulator of tumor progression in OSCC cells.
\end{abstract}

Correspondence to: Dr Yoshiki Mukudai, Department of Oral and Maxillofacial Surgery, School of Dentistry, Showa University, 2-1-1 Kitasenzoku, Ota-ku, Tokyo 145-8515, Japan

E-mail: mukudai@dent.showa-u.ac.jp

Key words: TPD52 family, TPD54, squamous cell carcinoma, tumorigenesis, integrin, metastasis

\section{Introduction}

The tumor protein D52 (TPD52) protein family consists of TPD52 (1), -53 (1-4), -54 (2,4), and -55 (5). The first identified protein of this family, TPD52, was found to be overexpressed in breast and lung cancers (6,7). Other family members have also been reported to be highly expressed in colon $(8,9)$, ovary (10-12), testis $(5,13)$, prostate $(14)$, and breast (15-17) cancers. Previous reports showed that overexpression of tpd52 in non-malignant 3T3 fibroblasts induces malignant transformation and increases cell proliferation and anchorageindependent growth $(18,19)$. Moreover, overexpression of $t p d 52$ led to an increase in cell proliferation as well as phosphorylation of Akt/protein kinase B (PKB) in prostate cancer (20-22) and also protected the cells from apoptosis induced by androgen deprivation via activation of the Stat $3 / \mathrm{Bcl}-2$ pathway (21). In addition, TPD52 regulates cell migration and invasion (23) and inhibits DNA damage repair (24). TPD53 regulates the cell cycle and is highly upregulated at the G2-M phase transition (25). TPD52, -53, and -54 also interact with each other through their coiled-coil domains (4). They also have numerous other binding partners, such as MAL2 (26), the phospholipid binding protein Annexin VI (27), the SNARE protein (Synaptobrevin 2), a main components of the SNARE complex (28), 14-3-3 (29), and adipose differentiation-related protein (ADRP) (30). These reports strongly suggest that TPD52 family protein members are important candidate targets of molecular therapy (31).

Signaling pathways such as mitogen-activated protein kinase (MAPK), Akt/PKB, and integrin signaling regulate cell proliferation (32), survival (33), and metastasis (34). Moreover, cross-talk of integrin signaling with MAPK signaling (35) and Akt/PKB signaling $(36,37)$ has been widely reported. Despite these findings, the direct effects of TPD52 family protein members on cell proliferation, migration, invasion, and metastasis in oral squamous cell carcinoma cell (OSCC) are still under investigation.

We recently reported (38) that TPD54 is highly expressed in both OSCC and in hyperplastic epidermal cells around cancer tissue. We also showed that TPD54 is a negative regulator of extracellular matrix (ECM)-dependent attachment and migration in OSCC (39). However, little is known 
concerning the detailed physiological and pathological functions of TPD54. Herein, as an extension of our previous study, we investigated in greater detail the expression of D52 proteins in OSCC tissue, and the effects of TPD52, -53 and -54 that underlie cell growth, migration, and invasion of OSCC cells. The results showed that TPD54 was overexpressed in both highly and poorly differentiated OSCC tissue, while the expression of TPD52 was not as high as that of TPD54. TPD53 was moderately expressed. Furthermore, TPD54 inhibited the colony formation and migration. These results indicated that overexpression of TPD54 negatively regulates tumor growth in vivo.

\section{Materials and methods}

Co-immunoprecipitation (Co-IP) analysis. Co-immunoprecipitation analysis was carried out using a commercial kit [Immunoprecipitation kit (Protein G), Sigma-Aldrich, St. Louis, MO, USA]. Subconfluent SAS cells in a 10-cm culture dish were lysed with the lysis buffer, and the total extract was immunoprecipitated with $5 \mu \mathrm{g}$ of anti-TPD52,-TPD53, -TPD54 or -GAPDH antibodies, or $5 \mu \mathrm{g}$ of pre-immune mouse IgG (described above), according to the manufacturer's protocol. Subsequently, the precipitated proteins were eluted in 1X SDS sample buffer (Bio-Rad, Hercules, CA, USA) containing $5 \%$ of 2-mercaptoethanol, and co-precipitating proteins were then analyzed by western blotting as described in another subsection.

Protein preparation and western blot analysis. Total cellular proteins were collected with Triton X-100 lysis buffer $[50 \mathrm{mM}$ Tris- $\mathrm{HCl}$ (pH 8.0), $300 \mathrm{mM} \mathrm{NaCl}, 0.5 \%$ Triton X-100, $5 \mathrm{mM}$ ethrylendiaminetetraacetic acid (EDTA), $1 \mathrm{mM}$ sodium $o$-vanadate] supplemented with Complete Mini protease inhibitor tablet (Roche Diagnostics, Mannheim, Germany) $48 \mathrm{~h}$ after gene-transfection. Protein concentrations were measured using the Quick Start Bradford reagent (Bio-Rad) with bovine serum albumin (BSA) as a standard. For western blot analysis, $20 \mu \mathrm{g}$ of total cellular protein was analyzed by sodium dodecyl sulfate polyacrylamide gel electrophoresis (SDS-PAGE) using a 4-20\% gradient gel (Bio-Rad) and blotted onto a polyvinylidene difluoride membrane using iBlot 2 (Thermo Fisher Scientific, Waltham, MA, USA). After blocking of non-specific binding with $0.2 \%$ non-fat dry milk (Cell Signaling Technology, Danvers, MA, USA) in Tris-buffered saline (Takara Bio, Shiga, Japan), the membrane was incubated with the following primary antibodies: anti-TPD52 [1/1,000 dilution; rabbit monoclonal antibody, Abcam, Branford, CT, USA (ab182578)]; anti-TPD53 [1/1,000 dilution; rabbit polyclonal antibody, Proteintech, Rosemont, IL, USA (14732-1-AP)]; anti-TPD54 [1/1,000 dilution; rabbit polyclonal antibody, Proteintech (11795-1-AP)]; anti-hemagglutinin (HA) [1/1,000 dilution; rabbit polyclonal antibody, Clontech, Mountain View, CA, USA (631207)]; anti-green fluorescent protein (GFP) [1/1,000 dilution; rabbit polyclonal antibody, Santa Cruz, Dallas, TX, USA (sc-8334)]; or anti-glyceraldehyde 3-phosphate dehydrogenase (GAPDH) [1/10,000 dilution; mouse monoclonal antibody, Sigma-Aldrich (G9295)] antibody and horseradish-peroxidase-conjugated secondary antibody (for rabbit, donkey polyclonal antibody (NA934V); for mouse,
Table I. Primer sequences for molecular constructs

Primer sequences

\begin{tabular}{ll}
\hline TPD52 & \\
Sense & 5'-GTCTGCTTATCAGGAGGGGC-3' \\
Antisense & 5'-GGCAGTGGGTAGCAGAACAA-3' \\
TPD53 & \\
Sense & 5'-GAGGTAACCAGAAGCGGCTA-3' \\
Antisense & 5'-ACAATGTCAAGGCCTGGGTT-3' \\
HA-tagged & \\
TPD52 & 5'-GAAGATCTACATGGATTGTAGAGAGATGGA-3' \\
Sense & 5'-GGGGTACCTCACAGGCTCTCCTGTGTCTTT-3' \\
Antisense & \\
HA-tagged & 5'-GAAGATCTACATGGAGGCGCAGGCACAAGG-3' \\
TPD53 & 5'-GGGGTACCTTAGCACTGCAGCTCCTCCTCC-3' \\
Antisense &
\end{tabular}

The sequences of primer pairs for cloning the coding regions of human $t p d 52,-53$ and for constructing HA-tagged tpd52, -53 cDNAs are shown.

sheep polyclonal antibody (NA931V) (GE Healthcare UK Ltd., Buckinghamshire, UK) as described previously (39). Subsequent washings were conducted using TBS-T. The protein bands were visualized using Amersham ECL Western Blotting Detection reagents (GE Healthcare UK Ltd.) and a ChemiDoc XRS Plus ImageLab System (Bio-Rad).

Clinical samples. All samples were acquired from patients who underwent treatment for squamous cell carcinoma in Showa University Dental Hospital from January 2001 through March 2015. All patients provided informed consent before enrollment in the study, in accordance with the protocol approved by the Institutional Review Board at Showa University Dental Hospital (approval no. DH2015-013). Primary lesions were resected from tongue (Fig. 2A-a-c and B-a, -b) and gingiva (Fig. 2B-c). Differentiation grade was determined according to the pathological reports submitted from the Division of Pathology, Department of Oral Diagnostic Sciences, School of Dentistry, Showa University.

Cell culture. SAS (40), HSC2, and HSC3 cells (41) (human oral squamous cell carcinoma-derived cell lines) were grown in high-glucose Dulbecco's modified Eagle's medium (HDMEM) (Wako, Osaka, Japan) supplemented with $10 \%$ fetal bovine serum (FBS), $100 \mathrm{U} / \mathrm{ml}$ penicillin, and $100 \mathrm{mg} / \mathrm{ml}$ streptomycin (Thermo Fisher Scientific) at $37^{\circ} \mathrm{C}$ in an atmosphere containing $5 \% \mathrm{CO}_{2}$.

Molecular constructs, small interfering RNA (siRNA) and gene transfection. The coding regions of human tpd52 and -53 cDNAs were amplified by an RT-PCR technique using singlestranded cDNA reverse-transcribed from total RNA of SAS cells that was used as a template. All of the primer sequences used are shown in Table I. Final concentrations of the primers were $10 \mu \mathrm{M}$, respectively. PCR cycles were $95^{\circ} \mathrm{C}$ for $3 \mathrm{~min}$; then, 
Table II. Primer sequences for the generation of stable clones.

Primer sequences

\begin{tabular}{cl}
\hline TPD52 OE & \\
Sense & 5'-ATGGATTGTAGAGAGATGGA-3' \\
Antisense & 5'-TCACAGGCTCTCCTGTGTCTTT-3' \\
TPD54 OE & \\
Sense & 5'-ATGGACTCCGCCGGCCAAGATATCAACCTG-3' \\
Antisense & 5'-TTAGAAAGGTGCGGGATCCGACAGGGGCTT-3' \\
TPD54 KD & \\
Sense & 5'-TGCTGTTCAAATTCATGCAAACGCGGGTTTTGGCCACTGACTGACCCGCGTTTATGAATTTGAA-3' \\
Antisense & 5'-CCTGTTCAAATTCATAAACGCGGGTCAGTCAGTGGCCAAAACCCGCGTTTGCATGAATTTGAAC-3' \\
\hline
\end{tabular}

The sequences of primer pairs for TOPO cloning of tpd52 and -54 [TPD52 and -54 overexpressed (OE)], and oligo DNAs for generating miRNAs for tpd54 [TPD54 knockdown (KD)] are shown. The underlined sequences are the TPD54 targeting sequences.

$94^{\circ} \mathrm{C}$ for $30 \mathrm{sec}, 60^{\circ} \mathrm{C}$ for $30 \mathrm{sec}, 72^{\circ} \mathrm{C}$ for $1 \mathrm{~min}(\mathrm{x} 40$ cycles); and followed by $72^{\circ} \mathrm{C}$ for $5 \mathrm{~min}$. The amplified products were subcloned into a pGEM T-Easy vector (Promega, Madison, WI, USA) using a TA-cloning technique. For construction of expression vectors of hemagglutinin (HA)-tagged human tpd52 and -53, cDNA of the coding region was amplified by PCR employing a sense- $B g l$ II-adaptor primer and an antisense $K p n I$-adaptor primer. The amplicons were double-digested with $B g l \mathrm{II}$ and $K p n I$ and inserted into the corresponding site of the pCMV-HA vector (Clontech Laboratories) as described previously (39). The resulting expression vectors were confirmed by sequencing using an ABI PRISM 310 Genetic Analyzer (Thermo Fisher Scientific) and the BigDye Terminator v3.1 Cycle Sequencing kit (Thermo Fisher Scientific). The expression vector for human tpd54 was that used in a previously described experiment (40). siRNA against human tpd52 and -54 was purchased from Sigma-Aldrich and Thermo Fisher Scientific, respectively. Control siRNA was purchased from Thermo Fisher Scientific. Expression vectors and siRNAs were transfected with Lipofectamine 2000 (Thermo Fisher Scientific) according to the manufacturer's protocol.

Generation of stable clones of cell lines.tpd52 and tpd54 overexpressing (OE) stable clones were obtained by using GFP Fusion TOPO TA Expression kits (Thermo Fisher Scientific). Singlestranded cDNAs were reverse-transcribed from total RNA of SAS cells that was used as a template. The amplified products were subcloned into a pcDNA3.1/NT-GFP-TOPO vector using TOPO cloning technology (Thermo Fisher Scientific). pcDNA3.1/NT-GFP (Thermo Fisher Scientific) was used as a control vector for OE experiments. TPD54 knocked-down (KD) stable clones were obtained by using BLOCK-iT Pol miR RNAi Expression Vector kits (Thermo Fisher Scientific). A double-stranded oligo targeting tpd54 was prepared by annealing two single-stranded oligos. The amplified products were subcloned into a pcDNA6.2-GW/Em-GFP-miR vector using Gateway cloning technology. pcDNA6.2-GW/ Em-GFP-miR-neg (Thermo Fisher Scientific) was used as a negative control miRNA vector. All of the primer sequences used are shown in Table II. The resulting expression vectors were verified by sequencing and were transfected with Lipofectamine 2000 (Thermo Fisher Scientific). To obtain tpd52 and tpd54 OE stable clones, transfected SAS cells were cultivated in the presence of $0.5 \mathrm{mg} / \mathrm{ml}$ of Geneticin (Thermo Fisher Scientific). tpd54 knock-down stable clones were obtained by cultivation in the presence of $50 \mu \mathrm{g} / \mathrm{ml}$ of Blasticidin $\mathrm{S} \mathrm{HCl}$ (Thermo Fisher Scientific), according to the manufacturer's protocol.

Cell growth assay. One thousand cells were seeded into a 96-well tissue culture plate in triplicate. After $48 \mathrm{~h}$, cell growth was assayed using the tetrazolium salt 3-(4,5-dimethylthiazol2-yl)-2,5-diphenyltetrazolium bromide (MTT) assay, as described previously (42). The experiment was performed in triplicate.

Anchorage-independent growth assay. The anchorage-independent growth assay was carried out by using a commercial kit (CytoSelect 96-Well In Vitro Tumor Sensitivity assay, Cell Biolabs, San Diego, CA, USA) according to the manufacturer's protocol. In total, 2500 transfected cells were grown in soft agar. After a week, the cells were examined under a microscope (Eclipse TS100/TS100-F, Nikon, Tokyo, Japan), photographed with a digital CCD camera (DS-Fil, Nikon), and formed colonies were counted (colonies/field). A colony was defined as a cell cluster that was $>50 \mu \mathrm{m}$ in diameter. Thereafter, cell growth was assayed using the MTT assay. The experiment was performed in triplicate.

Cell migration and invasion assays. Chemotaxis, haptotaxis, and invasion assays were carried out using a commercially available Boyden chamber kit (Chemotaxicell; Kurabo, Osaka, Japan). For the chemotaxis assay, the cells were starved in FBS-free medium for $24 \mathrm{~h}$ and then 10,000 of the transfected cells were seeded into a chamber inserted in a 24-well culture plate containing $10 \% \mathrm{FBS}$ as a chemotactic agent. After $48 \mathrm{~h}$, the cells were fixed with $10 \%$ formalin (Wako) and stained using crystal violet (43). Migrated cells were photographed, and the numbers of migrated cells were counted (cells/field). 
For the haptotaxis assay, the membranes were pre-coated with type I collagen (Nitta Gelatin Inc., Osaka, Japan), according to the manufacturer's protocol. Approximately 100,000 transfected cells were seeded into a chamber inserted in a 24-well culture plate. After $48 \mathrm{~h}$, the cells were fixed and stained using crystal violet. Migrated cells were photographed, and were then counted, as described for the chemotaxis assay. The wound healing assay was carried out as described previously (44). The transfected cells $(100,000)$ were seeded into a 24-well culture plate. Once the cells were confluent, a wound was made by scratching ( $0.9 \mathrm{~mm}$ width). After wound closure was first observed, the cells were fixed, stained using crystal violet and photographed. The wound width was then measured. For the invasion assay, the cells were starved in FBS-free medium for $24 \mathrm{~h}$. Similar to the chemotaxis assay, 10,000 of the transfected cells were seeded into a chamber, which was pre-coated with type I collagen (Nitta Gelatin Inc.), and was then inserted in a 24-well culture plate. After $48 \mathrm{~h}$, the cells were fixed and stained using crystal violet. Migrated cells were photographed and were counted in a manner similar to the chemotaxis and haptotaxis assays. Each experiment was performed in triplicate.

Mice. This study was approved by the Institutional Animal Care and Use Committee (approval no. 15024) and was carried out according to the Showa University Guidelines for Animal Experiments. Four-week-old female balb/c nu/nu mice $(n=3$ for each experimental group) were purchased from Clea Japan, Inc. (Tokyo, Japan) and were maintained under pathogenfree conditions. Approximately $1.0 \times 10^{7}$ cells in $100 \mu \mathrm{l}$ of phosphate-buffered saline (PBS) were injected subcutaneously into a unilateral flank. Tumor-bearing mice were treated with $1 \mathrm{nmol}$ of siRNAs (Koken, Tokyo, Japan) in $100 \mu \mathrm{l}$ of AteloGene (Koken), which were injected into subcutaneous spaces around tumor sections once a week for 7 weeks from day 7. The AteloGene and siRNA mixture was generated according to the manufacturer's protocol. At the end of the experiment, mice were sacrificed by $\mathrm{CO}_{2}$ asphyxiation, and resected tumor, liver, and lung were fixed in formalin (Wako) and stained with hematoxylin and eosin (H\&E) (Sakura Finetek Japan, Tokyo, Japan), as described previously (45). Tumor volume was determined by direct measurement, and was calculated using the formula $\pi / 6 \times$ (large diameter) $\mathrm{x}$

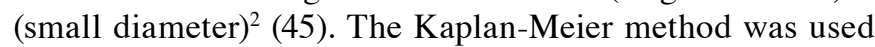
for survival analysis (46).

Immunohistochemistry. Resected specimens were fixed with $10 \%$ formalin, embedded in paraffin, stained with $\mathrm{H} \& \mathrm{E}$, and then immunohistochemically stained for TPD52 family proteins as described previously (46). Antigen retrieval was carried out with citrate-phosphate buffer $(0.01 \mathrm{M}, \mathrm{pH} 6.0)$ at $121^{\circ} \mathrm{C}$ for $20 \mathrm{~min}$. Endogenous peroxidases were blocked by incubating the sample with $10 \% \mathrm{H}_{2} \mathrm{O}_{2}$ (Wako) for $10 \mathrm{~min}$. Proteins were blocked using a commercial kit (Dako, Carpinteria,CA,USA) according to the manufacturer's protocol. The sections were incubated at $4^{\circ} \mathrm{C}$ overnight with primary antibodies (anti-TPD52 antibody, 1:50 dilution, rabbit polyclonal antibody; Biorbyt, Cambridgeshire, UK (orb100564); anti-TPD53 antibody, 1:200 dilution, rabbit polyclonal antibody, Proteintech (14732-1-AP); anti-TPD54 antibody, 1:200

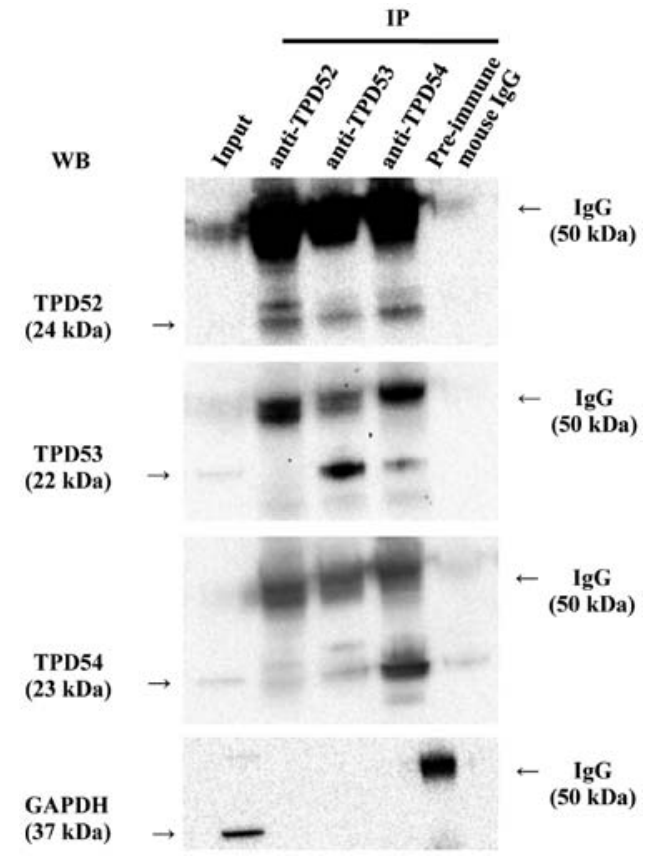

Figure 1. Co-immunoprecipitation analysis of TPD52 family proteins in SAS cells. Lysates of SAS cells were immunoprecipitated (IP) with anti-TPD52, -53 , or -54 antibodies or with pre-immune mouse IgG. Subsequently, the eluates were analyzed by western blotting (WB) for co-precipitated TPD52, -53 and -54. GAPDH was blotted as a control. In the leftmost lane, $20 \mu \mathrm{g}$ of total cellular proteins were loaded (input). At the left and right sides of the blot, the target proteins and co-precipitated IgG, together with their corresponding molecular weights, are shown.

dilution, rabbit polyclonal antibody, Proteintech (11795-1-AP); anti-cytokeratin 10/13, 1/200 dilution, mouse monoclonal antibody, Santa Cruz (DE-K13); control pre-immune IgG, 1/200 dilution, mouse IgG, Santa Cruz (sc-2762). The next day, the sections were incubated with secondary antibodies (EnVision ${ }^{+}$ system-HRP labelled polymer anti-rabbit/anti-mouse; Dako). Finally, sections were reacted with a 3, 3'-diaminobenzidine (DAB) peroxidase substrate kit (Dako) for color development and were examined under a microscope.

Statistical analysis. All values are expressed as means \pm standard deviation of triplicate data sets. The statistical significance of differences between groups was analyzed using a paired Student's t-test. A p-value of $<0.05$ was considered statistically significant.

\section{Compliance with ethical standards}

Ethical approval. All applicable international, national, and/ or institutional guidelines for the care and use of animals were followed. All procedures performed in studies involving animals were in accordance with the ethical standards of Showa University at which the studies were conducted. Animal experiments were approved by the Institutional Animal Care and Use Committee and were carried out according to the Showa University Guidelines for Animal Experiments (approval no. 15024). Regarding the management of specimens, before enrollment in the study, informed consent was obtained from all individual participants included in the study, in accordance with the protocol approved by the Institutional Review Board at Showa University Dental Hospital (approval 
A Highly differentiated $\mathrm{OSCCs}$

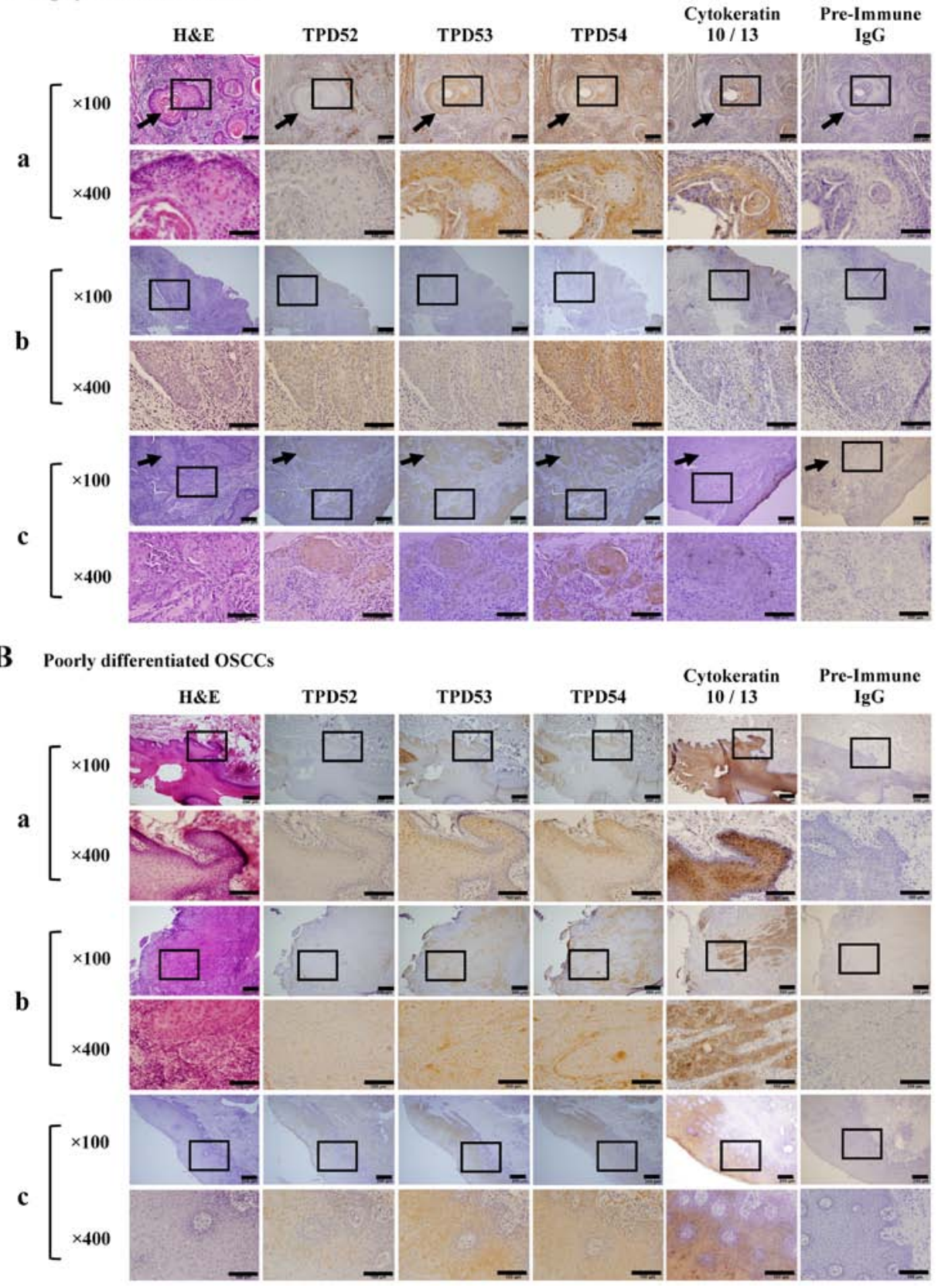

Figure 2. Expression of TPD52, -53 and -54 in oral squamous carcinoma specimens. Representative resected squamous carcinoma tissues from the tongue (A-a-c and B-a, -b) and gingiva (B-c) were stained with H\&E and were immunohistochemically stained for TPD52, -53 and -54 , cytokeratin 10/13 [positive control (47)], and pre-immune IgG (negative control). Optical microscopic images were captured at low (x100) and high (x400, area enclosed by a black box in the x100 image) magnification. Arrows indicate cancer pearl structures. Differentiation grade (high or poor) was determined according to pathological reports. Bars, $200 \mu \mathrm{m}$ (x100) and $100 \mu \mathrm{m}(\mathrm{x} 400)$.

no. DH2015-013). The experiments complied with the current laws of Japan.

\section{Results}

TPD52 family proteins form hetero-complexes. Since previous studies $(2,4)$ showed that TPD52 family proteins form homoand hetero-complexes in various cells, we investigated whether such molecular interactions were observed in SAS cells by a co-immunoprecipitation (co-IP) assay (Fig. 1). In western blotting of the total cellular protein (input), the blotted bands of TPD54, TPD53, and TPD52 gave strong, weak, and faint signals, respectively, in agreement with our previous study (39). Of more importance, TPD52, -53 , and -54 were found to co-immunoprecipitate with each other. Co-IP with control pre-immune mouse $\operatorname{IgG}$ indicated the specificity of the binding, despite the presence of a very faint pseudo-positive signal that was probably due to insufficient washing of the blots.

TPD54 is highly expressed in OSCC. We recently showed that TPD54 is highly expressed in oral squamous cell carcinomas (38). However, the expression of TPD52 and -53 in OSCC, and the differences in TPD52 family protein 


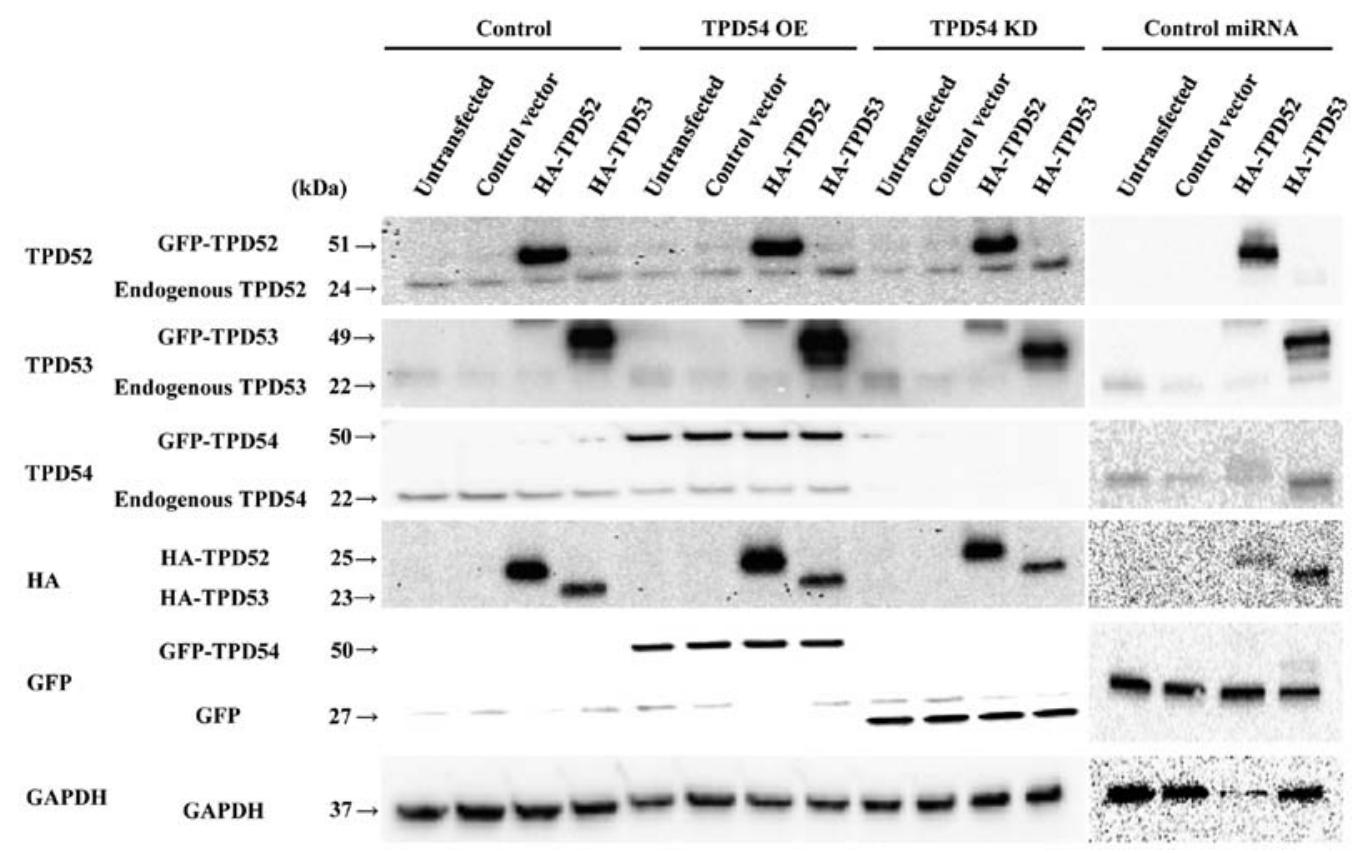

Figure 3. Western blot analysis of SAS cells with overexpression or knock-down of $t p d 54$ and/or overexpression of $t p d 52$ or -53 . Control-HA and HA-tpd52 and -53 expression vectors were transfected into cells of the SAS cell line in which GFP-empty (control), GFP-tpd54 (TPD54 OE) genes, GFP-tpd54miRNA (TPD54 KD), or control miRNA were stably expressed, or not (untransfected). After $48 \mathrm{~h}$, total cellular proteins were collected and analyzed by western blotting for TPD52, -53, and -54, HA, GFP, and GAPDH (an internal control) expression.

expression in highly and poorly differentiated tumors are still unclear. We therefore analyzed the detailed expression patterns of TPD52 family proteins in OSCC using immunohistochemical staining (Fig. 2). Three cases each of highly and poorly differentiated tumors were randomly chosen from tongue (Fig. 2A-a-c and B-a, -b) and gingiva (Fig. 2B-c). Differentiation grade was determined according to the pathological reports. Immunohistochemical staining showed that cytokeratin 10/13 [a marker of SCC cells (47)] was highly expressed in all of these OSCCs. A cancer 'pearl' structure was observed in some of the highly differentiated tissues (arrows in Fig. 2 indicate a typical cancer pearl structure), but was not observed in poorly differentiated tissue. Additionally, staining with pre-immune IgG (negative control) indicated the specificity of TPD52 family immune staining. In agreement with our previous study (38), TPD54 was highly expressed in the cancer region and the surrounding connective tissue, regardless of the tumor differentiation level. In contrast, the expression of TPD52 in either highly or poorly differentiated OSCC was lower than that of TPD54, and TPD52 was barely expressed in normal tissue. TPD53 was moderately expressed in the cancer region.

TPD54 inhibited colony formation in an anchorage-independent manner. The higher expression level of TPD54 compared to TPD52 and -53 suggested that TPD54 might play a more important role in OSCCs. Furthermore, our previous study (39) showed that TPD54 affects cell attachment to the ECM and cell migration of OSCC cells. Based on those findings, we hypothesized that TPD54 might be a key protein in OSCC cells, and might negatively affect tumor progression mediated by TPD52 and -53 . To further assess this possibility, $t p d 52$, -53 , and -54 were overexpressed in SAS cells. Additionally, in this experiment, HA-tagged tpd52 or -53 expression vectors were transfected into SAS cell lines that stably expressed GFP-tpd54 or GFP-miRNA against-tpd54. Subsequent western blot analysis (Fig. 3) showed that protein expression resulting from transient overexpression of $t p d 52$ or -53 and stable overexpression or knock-down of $t p d 54$ was observed as expected. Expression marker tags (HA and GFP) and internal control (GAPDH) proteins were also detected. Since expression profiles of control miRNA cell lines were similar to those of control cell lines (Fig. 3), protein expression in the control miRNA cell lines in further experiments are not shown to simplify the experiments. These cells were then assayed using an MTT assay of the monolayer cultured cells (Fig. 4A), a soft agar colony formation assay (Fig. 4B and C) and an MTT assay of the colonies formed in soft agar (Fig. 4D). Significant differences in cell growth between the control and several of the differently transfected cells were observed in the MTT assay of monolayer cultures ( ${ }^{*} \mathrm{p}<0.05$ versus control cells) (Fig. 4A), but the differences were smaller than those between the cells in colony formation assays (Fig. 4B-D). Colony formation of the tpd54-overexpressing cells was greatly limited in an anchorage-independent manner versus control cells, regardless of the co-expression of $t p d 52$ or $t p d 53$ (Fig. 4B). Conversely, knock-down of $t p d 54$ enhanced the number of colonies formed (Fig. 4C). MTT assay of the cells in this colony forming experiment showed no differences in cell growth (Fig. 4D), indicating that cell viability was not an important factor even in an anchorage-dependent culture. These findings suggested that TPD54 might be capable of attenuating the tumorigenicity of other TPD52 family proteins, and that TPD54 and other TPD52 family proteins might have opposite effects on primary tumor formation. Next, it was examined whether these effects on cell growth are reproduced in other OSCC cell lines, or not. The same experiments were carried out in $\mathrm{HSC} 2$ (Fig. 5) and HSC3 (Fig. 6) cells. HSC2 and HSC3 cells also showed 
A

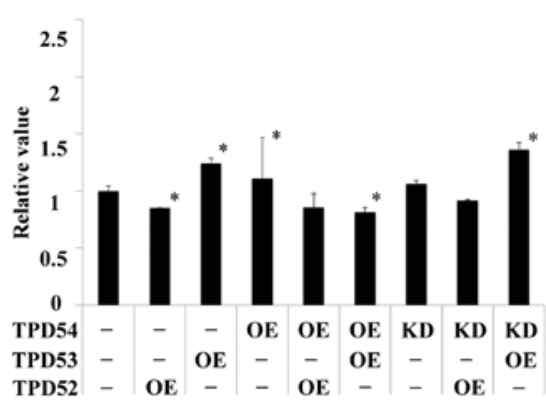

C

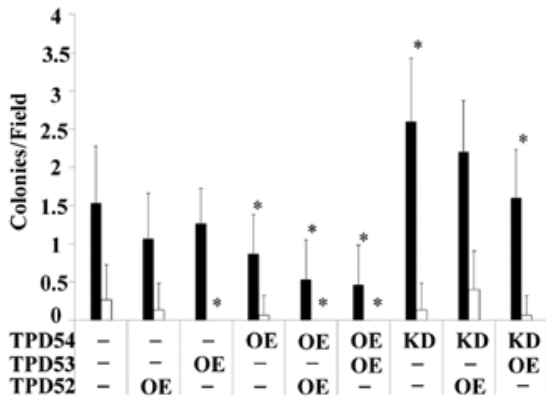

B

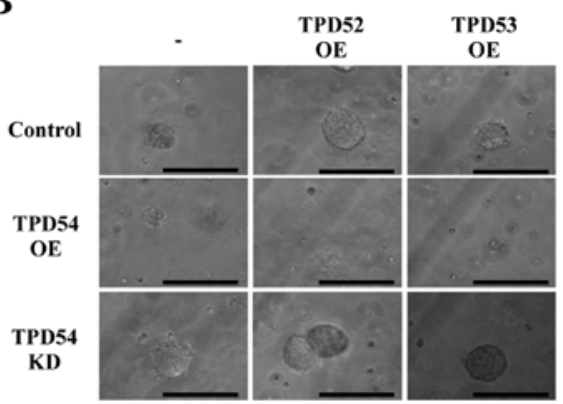

D

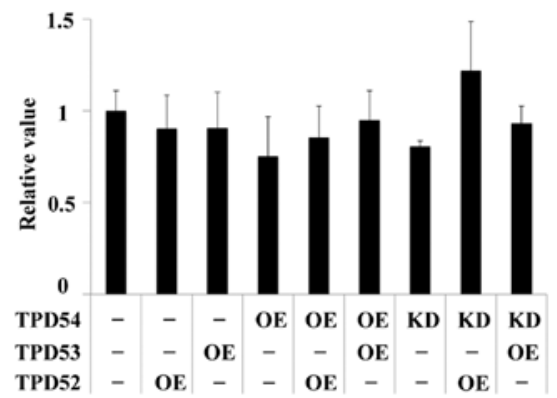

Figure 4. Effects of overexpression or knock-down of $t p d 54$ and/or of overexpression of $t p d 52$ and -53 on cell proliferation in SAS cells. Control-HA (-), HA-tpd52 (TPD52 OE), or -53 (TPD53 OE) expression vectors were transfected into SAS cells, in which GFP-empty (control) or GFP-tpd54 (TPD54 OE) genes or GFP-tpd54miRNA (TPD54 KD) were expressed. Cell growth was then analyzed using an MTT assay of cells in either monolayer culture (A) or in soft agar culture (D). Phase contrast analysis of colony formation in soft agar (B and C), and quantification of colony number are also shown. (A) MTT assay of monolayer cultures. The value in control cells was designated as ' 1 ' and relative values are shown. " $p<0.05$ versus control. (B-D) Colony formation and MTT assay of soft agar cultures. Bar, $200 \mu \mathrm{m}$ (B). The total number of colonies (black bars) and the number of colonies with a diameter $>100 \mu \mathrm{m}$ (white bars) were counted under a microscope. " $p<0.05$ versus control (C). At the end of the colony forming assay, the cells were analyzed using an MTT assay. The value in control cells was designated as ' 1 ' and relative values are shown (D).

A

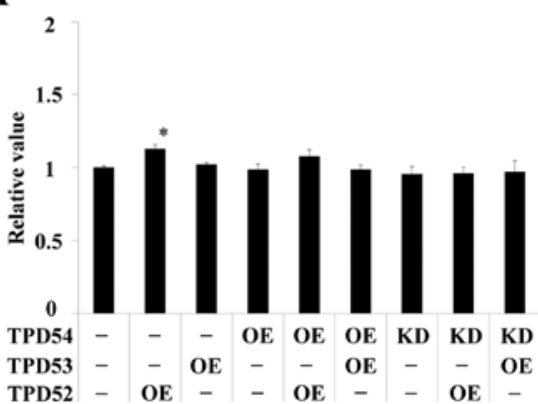

C

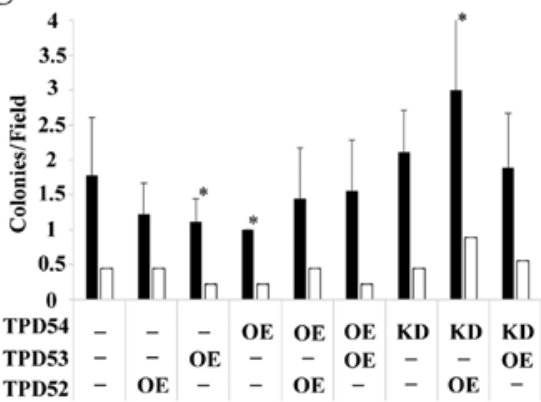

B

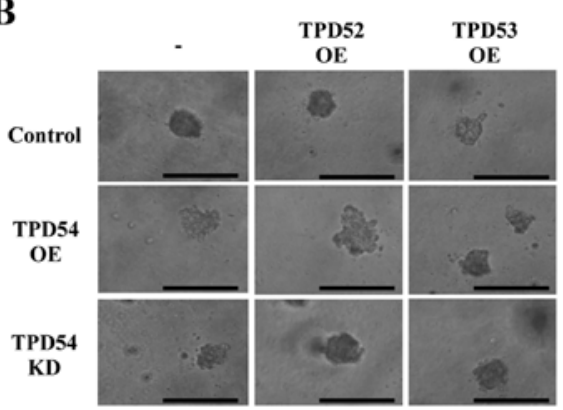

D

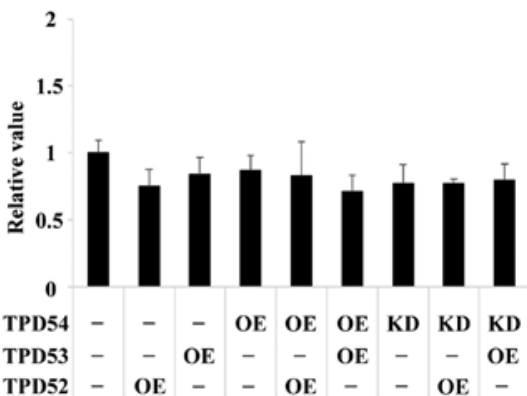

Figure 5. Effects of overexpression or knock-down of tpd54 and/or of overexpression of tpd52 and -53 on cell proliferation in HSC2 cells. Control-HA (-), HA-tpd52 (TPD52 OE), or -53 (TPD53 OE) expression vectors were transfected into HSC2 cells, in which GFP-empty (control) or GFP-tpd54 (TPD54 OE) genes or GFP-tpd54miRNA (TPD54 KD) were expressed. Cell growth was then analyzed using an MTT assay of cells in either monolayer culture (A) or in soft agar culture (D). Phase contrast analysis of colony formation in soft agar (B and C), and quantification of colony number are also shown. (A) MTT assay of monolayer cultures. The value in control cells was designated as ' 1 ' and relative values are shown. " $\mathrm{p}<0.05$ versus control. (B-D) Colony formation and MTT assay of soft agar cultures. Bar, $200 \mu \mathrm{m}$. (B) The total number of colonies (black bars) and the number of colonies with a diameter $>100 \mu \mathrm{m}$ (white bars) were counted under a microscope. "p $<0.05$ versus control (C). At the end of the colony forming assay, the cells were analyzed using an MTT assay. The value in control cells was designated as ' 1 ' and relative values are shown (D). 
A

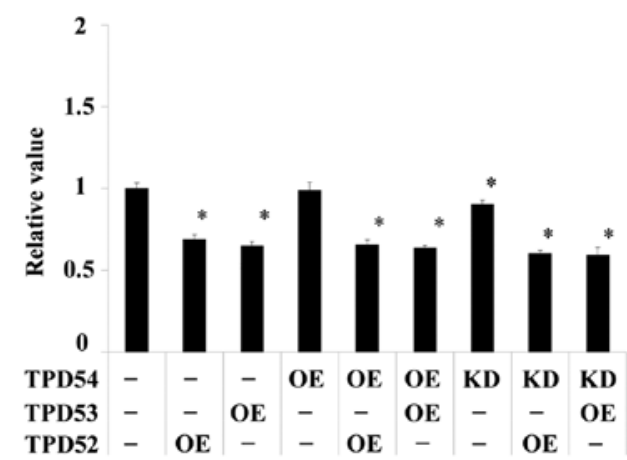

C

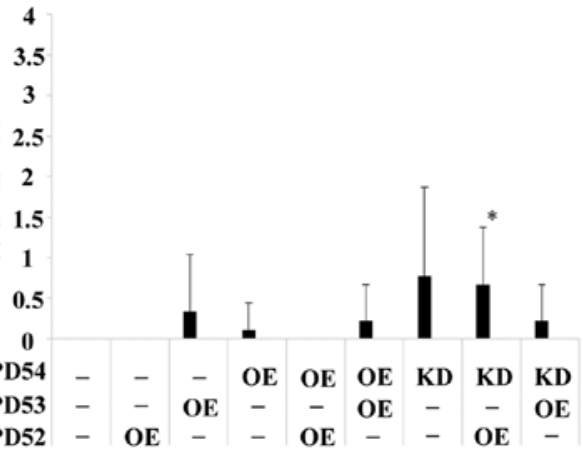

B

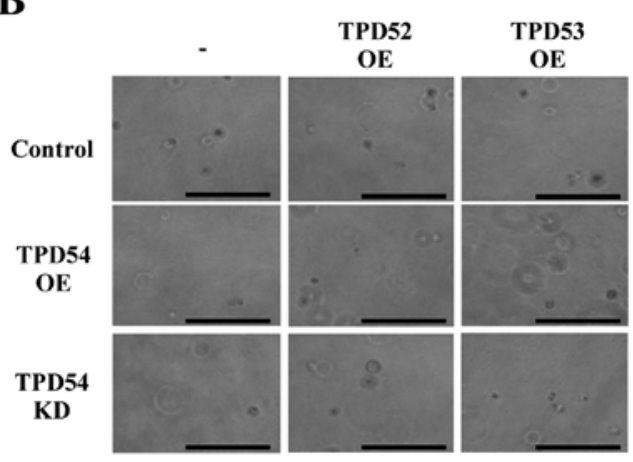

D

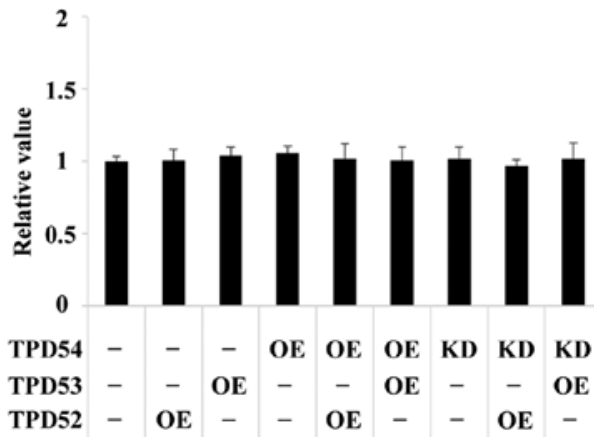

Figure 6. Effects of overexpression or knock-down of tpd54 and/or of overexpression of tpd52 and -53 on cell proliferation in HSC3 cells. Control-HA (-), HA-tpd52 (TPD52 OE), or -53 (TPD53 OE) expression vectors were transfected into HSC3 cells, in which GFP-empty (control) or GFP-tpd54 (TPD54 OE) genes or GFP-tpd54miRNA (TPD54 KD) were expressed. Cell growth was then analyzed using an MTT assay of cells in either monolayer culture (A) or in soft agar culture (D). Phase contrast analysis of colony formation in soft agar (B and C), and quantification of colony number are also shown. (A) MTT assay of monolayer cultures. The value in control cells was designated as 1 , and relative values are shown. " $\mathrm{p}<0.05$ versus control. (B-D) Colony formation and MTT assay of soft agar cultures. Bar, $200 \mu \mathrm{m}$ (B). The total number of colonies (black bars) and the number of colonies with a diameter $>100 \mu \mathrm{m}$ (white bars) were counted under a microscope. "p $<0.05$ versus control (C). At the end of the colony forming assay, the cells were analyzed using an MTT assay. The value in control cells was designated as ' 1 ' and relative values are shown (D).

significant differences between transfected cells versus control cells in an anchorage-independent manner in colony formation ( ${ }^{*} \mathrm{p}<0.05$ versus control cells) as well as in cell growth in a monolayer culture. However, the effects observed in HSC2 and HSC 3 cells were slightly different than those observed in SAS cells. Therefore, SAS cells, in which OE and KD of TPD52 proteins were the most effective were used as representative OSCC cells in the following experiments.

TPD54 downregulates the cell migration of OSCC-derived cells. Our previous report (39) showed that TPD54 plays a crucial role in the cell migration and invasion of OSCC cells. To further assess the effects of TPD52, -53 , and -54 on the cell migration of OSCC cells, we performed chemotaxis, haptotaxis and wound healing assays of the transfected cells (Fig. 7). tpd54 overexpression reduced cell migration versus control cells in a chemotaxis assay when expressed either alone or in combination with overexpression of $t p d 52$ or -53 (Fig. 7A). However, little effects on haptotaxis were observed following overexpression or knock-down of $t p d 54$ alone or combined with overexpression of $t p d 52$ or -53 (Fig. 7B). Overexpression of $t p d 52$ or -53 alone did not affect either chemotaxis or haptotaxis. tpd54overexpressing cells $\left(t p d 54^{+}, 53^{-}, 52^{-}\right)$showed decreased wound closure compared to control in a wound healing assay $(* \mathrm{p}<0.05$, Fig. 7C). No differences versus control were observed for the other experimental groups (Fig. 7C). We additionally investigated the effect of the different cell transfection combinations on cell invasion (Fig. 7D). However, cell invasion was barely modulated by any of these combinations. These results indicated that TPD54 might regulate cell migration through the modulation of molecular events such as integrin signaling.

tpd54 overexpression attenuated tumor growth in vivo. Since our previous in vitro study suggested that TPD54 has negative effects on cell proliferation and migration in OSCC cells, we further examined the ability of TPD54 to modulate tumor growth and/or metastasis in an in vivo study. The scheme of this study is outlined in Fig. 8A. In these experiments, one nanomole of siRNAs in Atelogene was injected once a week into each mouse ( $n=3$ per group) with a xenografted tumor of OSCC cells, in order to obtain sustainable knock-down of tpd52 or -54. A significant difference in body weight between the tpd54 overexpressing group and control was seen $\left({ }^{*} \mathrm{p}<0.05\right)$ (Fig. 8B) although no significant tumor suppression was observed in the tpd54 overexpressing group (Fig. 8C and E). However, contrary to our expectations, knock-down of $t p d 52$ in tpd54 overexpressing cells showed little effect on tumor growth. No significant differences in survival rate between the different groups of mice, as calculated by Kaplan-Meier's method, were observed (Fig. 8D). At the endpoint, specimens 
A

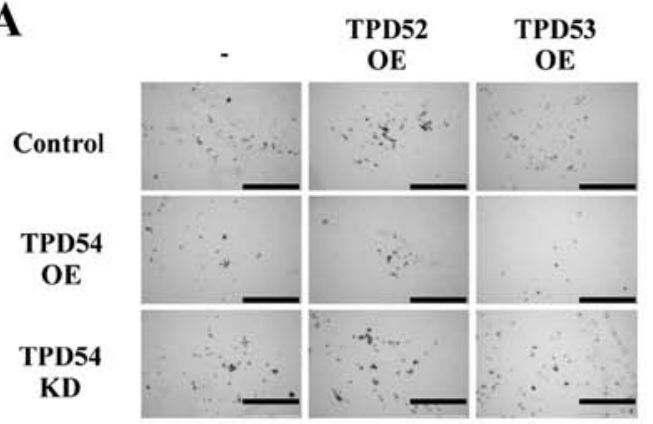

B

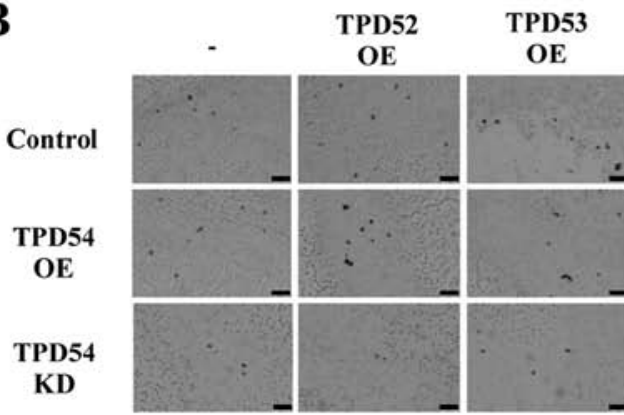

C

Control

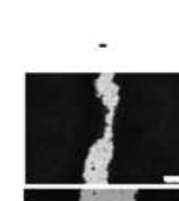

TPDS

OE

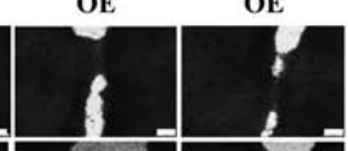

TPD54

OE
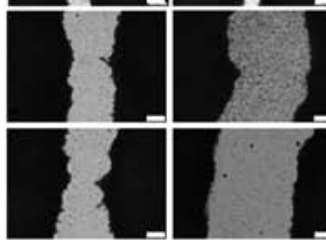

KD

D

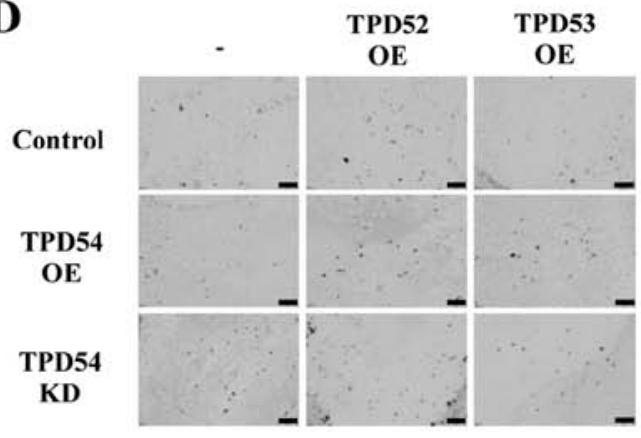

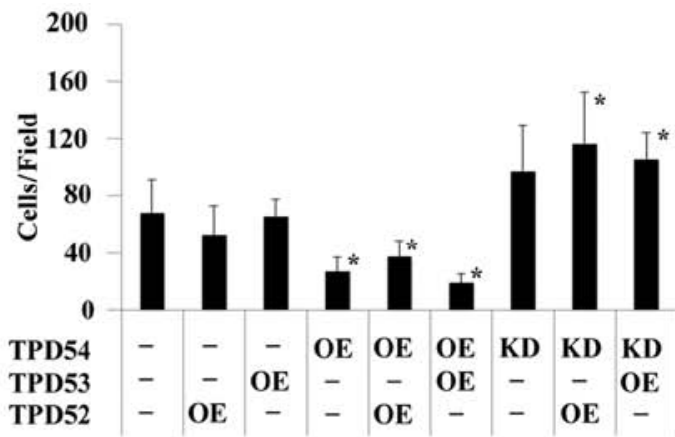
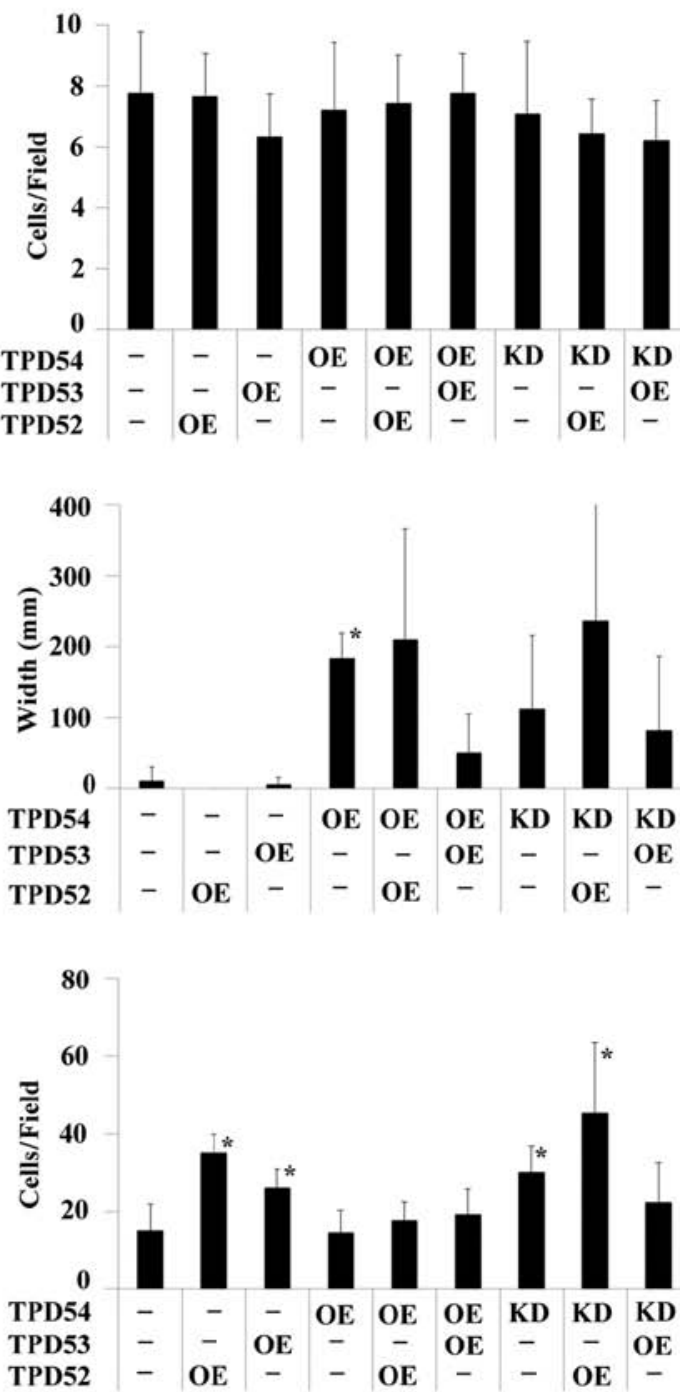

Figure 7. Effects of overexpression or knocking-down of tpd54, and/or overexpression of tpd52 and -53 on cell migration and invasion. Control-HA (-), or HA-tpd52 (TPD52 OE), -53 (TPD53 OE) expression vectors were transfected into SAS cells in which GFP-empty (control), GFP-tpd54 (TPD54 OE) genes, or GFP-tpd54shRNA (TPD54 KD) was stably expressed. One hundred thousand transfected cells were analyzed in chemotaxis (A), haptotaxis (B), wound healing (C), and cell invasion (D) assays. (A) Chemotaxis assay. Left and right panels show optical microscopic images and a graph of the number of migrated cells, respectively. Bar, $500 \mu \mathrm{m}$. ${ }^{*} \mathrm{p}<0.05$ versus control. (B) Haptotaxis assay. Left and right panels show optical microscopic images and a graph of the number of migrated cells, respectively. Bar, $100 \mu \mathrm{m}$. (C) Wound healing assay. Left and right panels show optical microscopic images and a graph of wound widths, respectively. Bar, $100 \mu \mathrm{m}$. "p $<0.05$ versus control. (D) Cell invasion assay. Left and right panels show optical microscopic images and a graph of the number of migrated cells, respectively. Bar, $200 \mu \mathrm{m}$. ${ }^{*} \mathrm{p}<0.05$ versus control. Details of each assay can be found in Materials and methods.

of the original tumor, and of lung and liver tissue were H\&E stained for confirmation of metastasis (Fig. 9). However, there were few histological differences between the groups. Metastasis was not observed in any group by microscopic examination. These results indicated that TPD54 might function as a negative regulator of tumor growth, suggesting that interactions between TPD52 family protein members might be involved in the growth of OSCC. 
A

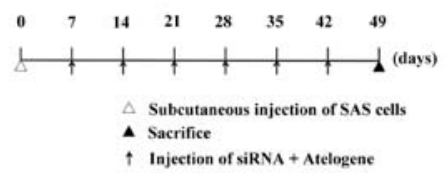

C

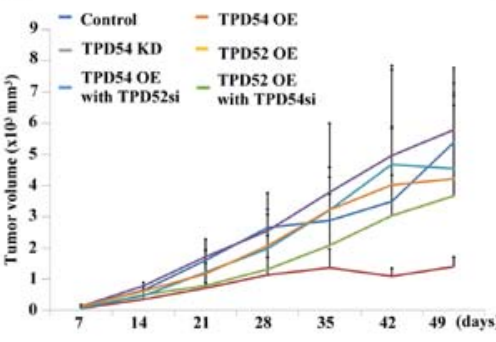

D

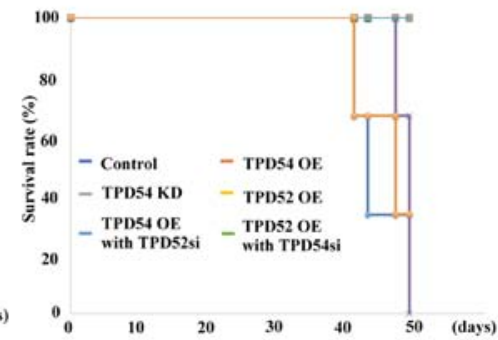

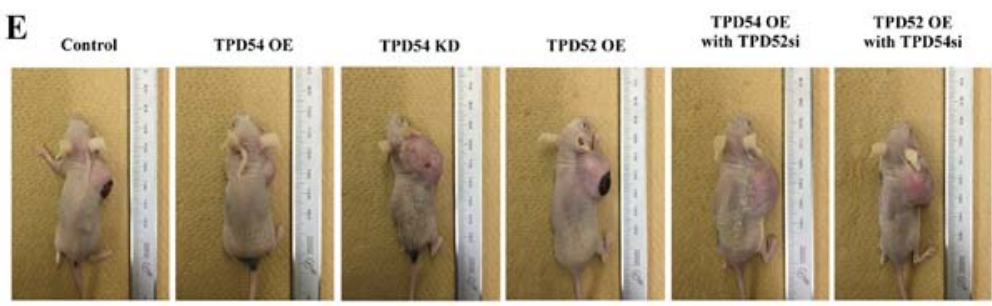

Figure 8. Effects of overexpression or knock-down of tpd52 and -54 on body weight, tumor growth and survival rate in tumor-xenografted mice. SAS cells, in which GFP-empty (control), GFP-tpd54 (TPD54 OE), GFP-tpd54miRNA (TPD54 KD), GFP-tpd52 (TPD52 OE), GFP-tpd54 with $t p d 52$ siRNA (TPD54 OE with TPD52si), or GFP-tpd52 with tpd54siRNA (TPD52 OE with TPD54si) stably expressed were used. (A) A schematic outline of the tumor-xenograft study. (B) The average body weight of the mice. (C) The average tumor volume of the mice. (D) Kaplan Meier analysis of the survival rate of the mice. (E) Representative photographic images of tumor-xenografted mice at the end point (day 49).

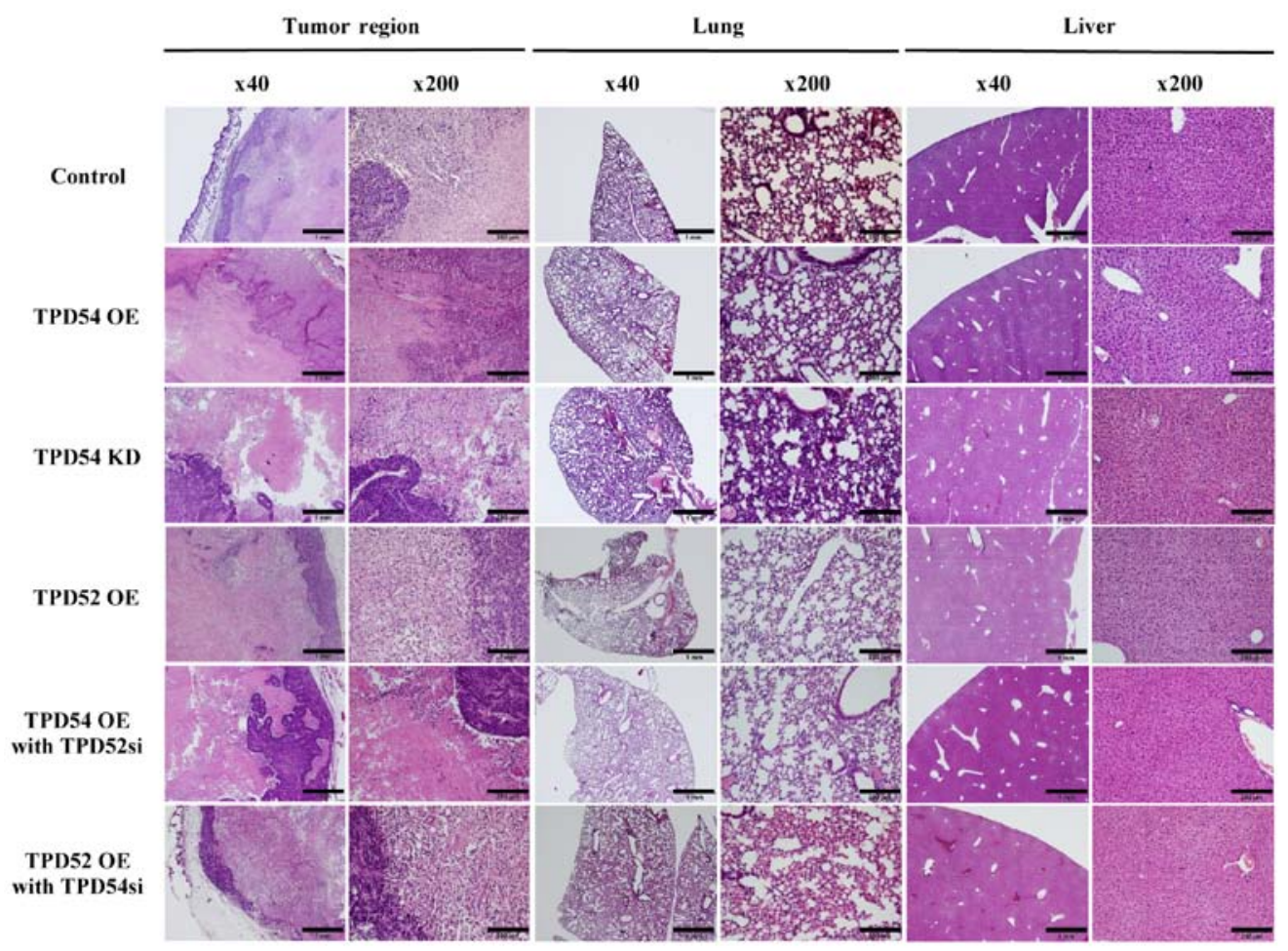

Figure 9. Histopathological evaluation of the original tumor, and of lung and liver from tumor-xenografted mice. SAS cells, in which GFP-empty (control), GFP-tpd54 (TPD54 OE), GFP-tpd54miRNA (TPD54 KD), GFP-tpd52 (TPD52 OE), GFP-tpd54 with $t p d 52 \mathrm{siRNA}$ (TPD54 OE with TPD52si) or GFP-tpd52 with $t p d 54$ siRNA (TPD52 OE with TPD54si) stably expressed were used. All slides were photographed at low (x40; bar, $1 \mathrm{~mm}$ ) and high (x200; bar, $200 \mu \mathrm{m}$ ) magnification. 


\section{Discussion}

Tumor protein D52 (TPD52) family members are expressed in several types of cancers, including OSCC (5-17). Additionally, the cellular functions of this family have been widely studied. Previous reports indicated that overexpression of $t p d 52$ in nonmalignant 3T3 fibroblasts induced an increase in the growth rate and also enabled the cells to exist in an anchorage-independent manner in vitro and to undergo metastatic growth in vivo (18). Moreover, overexpression of $t p d 52$ led to increased tumor growth in cancer cells (48). Downregulation of tpd52 led to a decrease in cell migration, invasion (23), and apoptosis (20). TPD53 regulates the cell cycle and is highly upregulated at the G2-M phase transition (25). However, little is known about the cellular functions of TPD54, particularly in OSCCs. We recently showed that TPD54 is expressed in OSCCs and in nearby hypertrophic squamous cells, and we suggested that this protein might be a candidate marker of oral epithelial carcinogenesis (38). The expression of TPD52 and -53 in OSCC and differences in their expression in high and poor differentiation stages of OSCC are still unclear. We therefore determined the detailed expression patterns of TPD52 family proteins in OSCC (Fig. 1). Indeed, TPD54 was highly expressed in the cancer region, regardless of the differentiation stage. However, TPD52 was expressed at a lower level than TPD54 in either highly or poorly differentiated OSCC. TPD53 was moderately expressed in the cancer region. A previous report (4) indicated homo- or heteromeric interactions between TPD52, -53, and -54 and suggested that these proteins might play several kinds of roles in cancer progression. These combined data suggested that TPD52 and TPD54 interact with each other and that these proteins, in particular TPD54, play important roles in cancer progression in OSCC. In the present study, co-IP experiments (Fig. 1) confirmed interactions between those TPD family proteins, suggesting that they do form hetero-protein complexes on OSCC cells. Furthermore, in our previous experiments involving $t p d 54$ overexpression or knock-down in OSCC-derived SAS cells, we observed little effects on cell proliferation, caspase activity, MMP activity or cell invasion in monolayer cultures (39). However, tpd54 overexpression led to a decrease in anchorage-independent proliferation, regardless of apoptosis (39). In the present study, we investigated in more detail the cellular effects of expression levels of TPD52 family proteins by using gene co-expression. These studies indicated little differences in cell proliferation between several differently transfected cells in a monolayer culture. However, in anchorage-independent culture, strong suppression of colony formation was observed in $t p d 54$ overexpressing cells, regardless of the co-expression of $t p d 52$ or $t p d 53$. In addition, knock-down of tpd54 enhanced colony formation. The correlation between anchorage-independent proliferation and the in vivo behavior of cells is well established $(49,50)$. The combination of these data with our previous results suggested a significant involvement of TPD54 in tumor growth in the modulation of cancer metastasis. These results prompted us to further assess the combinatorial effects of TPD52 family proteins on cell migration and invasion. These assays showed that TPD54 negatively controls cell migration, leading us to hypothesize that TPD52 proteins might modulate the affinity of integrins for the ECM (39).
Since these in vitro results suggested that TPD54 has negative effects on cell proliferation and migration in OSCC cells, we examined the involvement of TPD54 in tumor growth in vivo. In those experiments, a significant difference in body weight between tpd54 overexpressing mice and controls was seen, although no significant tumor suppressive effect was observed in this group. However, tumor growth in several other experimental groups with different combinations of TPD-family proteins did not agree with our expectations. We therefore consider that several as yet unknown molecular pathways might be involved, and/or that homo- and heteromeric interactions of TPD52 family proteins through their coiled-coil motif with each other or with other heteromeric partners $(4,26,28,29,51-53)$ are likely to participate in tumor growth regulation by these proteins. Li et al (54) reported that prostate leucine zipper (PrLZ), which is a TPD52 isoform, is highly expressed in prostate cancers and interacts with the androgen receptor. We consider that this interaction may also occur in OSCC cells. Analysis of the effects of such an interaction on consequent interactions of TPD52 family proteins might be essential in order to solve this issue. The details of TPD52 family interactions are still unclear, particularly in OSCC cells. We are currently in the process of investigating the cellular growth, invasion and metastasis mediated by the interaction of TPD52 family protein members. He et al recently reported that TPD54 has a role in the promotion of cancer progression in OSCC cell lines (55), which is the opposite result to the present study. This discrepancy may be due to the different cells used in the two studies. Thus, the CAL27 and KB cell lines that they employed in their experiments are an oral adenosquamous carcinoma cell line (56) and a HeLa contaminant-epidermal carcinoma cell line (57), respectively. However, the OSCC cells that we employed are SAS cells, which were isolated from tongue OSCC (40). These cells might harbor cells with more of the original phenotypes of OSCC cells. In any case, more detailed investigations are required in the future in order to address this discrepancy.

For tumor therapy, molecular targeted therapies are currently in the spotlight, next to surgery, radiation, and chemotherapy. TPD52 family proteins are also considered as novel candidate target proteins since these proteins are expressed in many types of cancers (31). In conclusion, our study showed that TPD54 acts as a negative regulator of anchorage-independent proliferation and cell migration of OSCC cells in vitro. Moreover, TPD54 decreased body weight gain and tended to attenuate tumor growth in vivo. These combined data suggest that an increase in the expression of tpd54 might improve outcomes in OSCC patients. As yet, only a few studies of TPD54 have been reported. Further investigation of TPD54 is still required.

\section{Acknowledgements}

This study was supported by Grants-in-Aid for Scientific Research (KAKENHI) from the Japan Society for the Promotion of Science (JSPS) [KAKENHI C to Y.M. (15K11301), S.K. (24593060) and T.S. (15K11269)]. The whole manuscript was proofread by FOLTE (Tokyo, Japan). The authors wish to thank all of the staff at the Department of Oral and Maxillofacial Surgery, School of Dentistry, Showa 
University for their helpful suggestions; Dr Kenji Mishima of the Division of Pathology, Department of Oral Diagnostic Sciences, School of Dentistry, Showa University for pathological diagnostic advice; and Ms. Miho Yoshihara for secretarial assistance.

\section{References}

1. Byrne JA, Mattei MG and Basset P: Definition of the tumor protein D52 (TPD52) gene family through cloning of D52 homologues in human (hD53) and mouse (mD52). Genomics 35: 523-532, 1996

2. Nourse CR, Mattei MG, Gunning P and Byrne JA: Cloning of a third member of the D52 gene family indicates alternative coding sequence usage in D52-like transcripts. Biochim Biophys Acta 1443: 155-168, 1998.

3. Byrne JA, Mattei MG, Basset P and Gunning P: Identification and in situ hybridization mapping of a mouse Tpd5211 (D53) orthologue to chromosome 10A4-B2. Cytogenet Cell Genet 81: 199-201, 1998.

4. Byrne JA, Nourse CR, Basset P and Gunning P: Identification of homo- and heteromeric interactions between members of the breast carcinoma-associated D52 protein family using the yeast two-hybrid system. Oncogene 16: 873-881, 1998

5. Cao Q, Chen J, Zhu L, Liu Y, Zhou Z, Sha J, Wang S and Li J: A testis-specific and testis developmentally regulated tumor protein D52 (TPD52)-like protein TPD52L3/hD55 interacts with TPD52 family proteins. Biochem Biophys Res Commun 344: 798-806, 2006.

6. Byrne JA, Tomasetto C, Garnier JM, Rouyer N, Mattei MG, Bellocq JP, Rio MC and Basset P: A screening method to identify genes commonly overexpressed in carcinomas and the identification of a novel complementary DNA sequence. Cancer Res 55: 2896-2903, 1995.

7. Chen SL, Maroulakou IG, Green JE, Romano-Spica V, Modi W, Lautenberger $\mathrm{J}$ and Bhat NK: Isolation and characterization of a novel gene expressed in multiple cancers. Oncogene 12: 741-751, 1996.

8. Malek RL, Irby RB, Guo QM, Lee K, Wong S, He M, Tsai J, Frank B, Liu ET, Quackenbush J, et al: Identification of Src transformation fingerprint in human colon cancer. Oncogene 21: 7256-7265, 2002.

9. Petrova DT, Asif AR, Armstrong VW, Dimova I, Toshev S, Yaramov N, Oellerich M and Toncheva D: Expression of chloride intracellular channel protein 1 (CLIC1) and tumor protein D52 (TPD52) as potential biomarkers for colorectal cancer. Clin Biochem 41: 1224-1236, 2008.

10. Byrne JA, Balleine RL, Schoenberg Fejzo M, Mercieca J, Chiew YE, Livnat Y, St Heaps L, Peters GB, Byth K, Karlan BY, et al: Tumor protein D52 (TPD52) is overexpressed and a gene amplification target in ovarian cancer. Int J Cancer 117: 1049-1054, 2005.

11. Byrne JA, Maleki S, Hardy JR, Gloss BS, Murali R, Scurry JP, Fanayan S, Emmanuel C, Hacker NF, Sutherland RL, et al: MAL2 and tumor protein D52 (TPD52) are frequently overexpressed in ovarian carcinoma, but differentially associated with histological subtype and patient outcome. BMC Cancer 10: 497, 2010.

12. Fejzo MS, Dering J, Ginther C, Anderson L, Ramos L, Walsh C, Karlan B and Slamon DJ: Comprehensive analysis of 20q13 genes in ovarian cancer identifies ADRM1 as amplification target. Genes Chromosomes Cancer 47: 873-883, 2008.

13. Willems A, De Gendt K, Allemeersch J, Smith LB, Welsh M, Swinnen JV and Verhoeven G: Early effects of Sertoli cell-selective androgen receptor ablation on testicular gene expression. Int J Androl 33: 507-517, 2010.

14. Rubin MA, Varambally S, Beroukhim R, Tomlins SA, Rhodes DR, Paris PL, Hofer MD, Storz-Schweizer M, Kuefer R, Fletcher JA, et al: Overexpression, amplification, and androgen regulation of TPD52 in prostate cancer. Cancer Res 64: 3814-3822, 2004.

15. Chen H, Pimienta G, Gu Y, Sun X, Hu J, Kim MS, Chaerkady R, Gucek M, Cole RN, Sukumar S, et al: Proteomic characterization of Her2/neu-overexpressing breast cancer cells. Proteomics 10: 3800-3810, 2010.

16. Crugliano T, Quaresima B, Gaspari M, Faniello MC, Romeo F, Baudi F, Cuda G, Costanzo F and Venuta S: Specific changes in the proteomic pattern produced by the BRCA1-Ser1841Asn missense mutation. Int J Biochem Cell Biol 39: 220-226, 2007.
17. Scanlan MJ, Gout I, Gordon CM, Williamson B, Stockert E, Gure AO, Jäger D, Chen YT, Mackay A, O'Hare MJ, et al: Humoral immunity to human breast cancer: Antigen definition and quantitative analysis of mRNA expression. Cancer Immun 1: 4, 2001.

18. Lewis JD, Payton LA, Whitford JG, Byrne JA, Smith DI, Yang L and Bright RK: Induction of tumorigenesis and metastasis by the murine orthologue of tumor protein D52. Mol Cancer Res 5: 133-144, 2007.

19. Shehata M, Bièche I, Boutros R, Weidenhofer J, Fanayan S, Spalding L, Zeps N, Byth K, Bright RK, Lidereau R, et al: Nonredundant functions for tumor protein D52-like proteins support specific targeting of TPD52. Clin Cancer Res 14: 5050-5060, 2008.

20. Ummanni R, Teller S, Junker H, Zimmermann U, Venz S, Scharf C, Giebel J and Walther R: Altered expression of tumor protein D52 regulates apoptosis and migration of prostate cancer cells. FEBS J 275: 5703-5713, 2008.

21. Zhang D, He D, Xue Y, Wang R, Wu K, Xie H, Zeng J, Wang X, Zhau HE, Chung LW, et al: PrLZ protects prostate cancer cells from apoptosis induced by androgen deprivation via the activation of Stat3/Bcl-2 pathway. Cancer Res 71: 2193-2202, 2011.

22. Zhang H, Wang J, Pang B, Liang RX, Li S, Huang PT, Wang R, Chung LW, Zhau HE, Huang C, et al: PC-1/PrLZ contributes to malignant progression in prostate cancer. Cancer Res 67: 8906-8913, 2007

23. Zhao P, Zhong W, Ying X, Yao B, Yuan Z, Fu J and Zhou Z: Comparative proteomic analysis of anti-benzo(a)pyrene-7,8-dihydrodiol-9,10-epoxide-transformed and normal human bronchial epithelial G0/G1 cells. Chem Biol Interact 186: 166-173, 2010.

24. Sims AH, Finnon P, Miller CJ, Bouffler SD, Howell A, Scott D and Clarke RB: TPD52 and NFKB1 gene expression levels correlate with G2 chromosomal radiosensitivity in lymphocytes of women with and at risk of hereditary breast cancer. Int J Radiat Biol 83: 409-420, 2007.

25. Boutros R, Fanayan S, Shehata M and Byrne JA: The tumor protein D52 family: Many pieces, many puzzles. Biochem Biophys Res Commun 325: 1115-1121, 2004.

26. Wilson SH, Bailey AM, Nourse CR, Mattei MG and Byrne JA: Identification of MAL2, a novel member of the mal proteolipid family, though interactions with TPD52-like proteins in the yeast two-hybrid system. Genomics 76: 81-88, 2001.

27. Thomas DD, Kaspar KM, Taft WB, Weng N, Rodenkirch LA and Groblewski GE: Identification of Annexin VI as a $\mathrm{Ca}^{2+}$-sensitive CRHSP-28-binding protein in pancreatic acinar cells. J Biol Chem 277: 35496-35502, 2002.

28. Proux-Gillardeaux V, Galli T, Callebaut I, Mikhailik A, Calothy G and Marx M: D53 is a novel endosomal SNARE-binding protein that enhances interaction of syntaxin 1 with the synaptobrevin 2 complex in vitro. Biochem J 370: 213-221, 2003.

29. Boutros R, Bailey AM, Wilson SHD and Byrne JA: Alternative splicing as a mechanism for regulating 14-3-3 binding: Interactions between hD53 (TPD52L1) and 14-3-3 proteins. J Mol Biol 332: 675-687, 2003.

30. Kamili A, Roslan N, Frost S, Cantrill LC, Wang D, DellaFranca A, Bright RK, Groblewski GE, Straub BK, Hoy AJ, et al: TPD52 expression increases neutral lipid storage within cultured cells. J Cell Sci 128: 3223-3238, 2015.

31. Byrne JA, Frost S, Chen Y and Bright RK: Tumor protein D52 (TPD52) and cancer-oncogene understudy or understudied oncogene? Tumour Biol 35: 7369-7382, 2014.

32. Zhang W and Liu HT: MAPK signal pathways in the regulation of cell proliferation in mammalian cells. Cell Res 12: 9-18, 2002.

33. Manning BD and Cantley LC: AKT/PKB signaling: Navigating downstream. Cell 129: 1261-1274, 2007.

34. Fornaro M, Manes T and Languino LR: Integrins and prostate cancer metastases. Cancer Metastasis Rev 20: 321-331, 2001.

35. Wu WS: The signaling mechanism of ROS in tumor progression. Cancer Metastasis Rev 25: 695-705, 2006.

36. Bhaskar PT and Hay N: The two TORCs and Akt. Dev Cell 12: 487-502, 2007.

37. Legate KR, Wickström SA and Fässler R: Genetic and cell biological analysis of integrin outside-in signaling. Genes Dev 23: 397-418, 2009.

38. Fujita A and Kondo S: Identification of TPD54 as a candidate marker of oral epithelial carcinogenesis. J Oral Maxillofac Surg Med Pathol 27: 770-774, 2015.

39. Mukudai Y, Kondo S, Fujita A, Yoshihama Y, Shirota T and Shintani S: Tumor protein D54 is a negative regulator of extracellular matrix-dependent migration and attachment in oral squamous cell carcinoma-derived cell lines. Cell Oncol (Dordr) 36: $233-245,2013$. 
40. Takahashi K: Establishment and characterization of a cell line(SAS) from poorly differentiated human squamous cell carcinoma of the tongue. Jpn Stomatological Soc 38: 20-28, 1989.

41. Momose F, Araida T, Negishi A, Ichijo H, Shioda S and Sasaki S: Variant sublines with different metastatic potentials selected in nude mice from human oral squamous cell carcinomas. J Oral Pathol Med 18: 391-395, 1989.

42. Tsukamoto H, Kondo S, Mukudai Y, Nagumo T, Yasuda A, Kurihara Y, Kamatani T and Shintani S: Evaluation of anticancer activities of benzo[c]phenanthridine alkaloid sanguinarine in oral squamous cell carcinoma cell line. Anticancer Res 31: 2841-2846, 2011.

43. Enomoto-Iwamoto M, Iwamoto M, Mukudai Y, Kawakami Y, Nohno T, Higuchi Y, Takemoto S, Ohuchi H, Noji S and Kurisu K Bone morphogenetic protein signaling is required for maintenance of differentiated phenotype, control of proliferation, and hypertrophy in chondrocytes. J Cell Biol 140: 409-418, 1998.

44. Chen Y, Lu B, Yang Q, Fearns C, Yates JR III and Lee JD: Combined integrin phosphoproteomic analyses and small interfering RNA - based functional screening identify key regulators for cancer cell adhesion and migration. Cancer Res 69: 3713-3720, 2009.

45. Yasuda A, Kondo S, Nagumo T, Tsukamoto H, Mukudai Y, Umezawa K and Shintani S: Anti-tumor activity of dehydroxymethylepoxyquinomicin against human oral squamous cell carcinoma cell lines in vitro and in vivo. Oral Oncol 47: 334-339, 2011.

46. Shiogama S, Yoshiba S, Soga D, Motohashi H and Shintani S: Aberrant expression of EZH2 is associated with pathological findings and P53 alteration. Anticancer Res 33: 4309-4317, 2013.

47. Mukudai Y, Zhang M, Shiogama S, Kondo S, Ito C, Motohashi H, Kato K, Fujii M, Shintani S, Shigemori H, et al: Methanol and butanol extracts of Paeonia lutea leaves repress metastasis of squamous cell carcinoma. Evid Based Complement Alternat Med 2016: 6087213, 2016.
48. Wang R, Xu J, Mabjeesh N, Zhu G, Zhou J, Amin M, He D, Marshall FF, Zhau HE and Chung LW: PrLZ is expressed in normal prostate development and in human prostate cancer progression. Clin Cancer Res 13: 6040-6048, 2007.

49. Cifone MA and Fidler IJ: Correlation of patterns of anchorageindependent growth with in vivo behavior of cells from a murine fibrosarcoma. Proc Natl Acad Sci USA 77: 1039-1043, 1980.

50. Hahn WC, Counter CM, Lundberg AS, Beijersbergen RL, Brooks MW and Weinberg RA: Creation of human tumour cells with defined genetic elements. Nature 400: 464-468, 1999.

51. Chen SL,Zhang XK, Halverson DO, Byeon MK, Schweinfest CW, Ferris DK and Bhat NK: Characterization of human N8 protein. Oncogene 15: 2577-2588, 1997.

52. Proux V, Provot S, Felder-Schmittbuhl MP, Laugier D, Calothy G and Marx M: Characterization of a leucine zipper-containing protein identified by retroviral insertion in avian neuroretina cells. J Biol Chem 271: 30790-30797, 1996.

53. Sathasivam P, Bailey AM, Crossley M and Byrne JA: The role of the coiled-coil motif in interactions mediated by TPD52. Biochem Biophys Res Commun 288: 56-61, 2001.

54. Li L, Xie H, Liang L, Gao Y, Zhang D, Fang L, Lee SO, Luo J, Chen X, Wang X, et al: Increased PrLZ-mediated androgen receptor transactivation promotes prostate cancer growth at castration-resistant stage. Carcinogenesis 34: 257-267, 2013.

55. He Y, Chen F, Cai Y and Chen S: Knockdown of tumor protein D52-like 2 induces cell growth inhibition and apoptosis in oral squamous cell carcinoma. Cell Biol Int 39: 264-271, 2015.

56. Jiang L, Ji N, Zhou Y, Li J, Liu X, Wang Z, Chen Q and Zeng X: CAL 27 is an oral adenosquamous carcinoma cell line. Oral Oncol 45: e204-e207, 2009.

57. Eagle H: Propagation in a fluid medium of a human epidermoid carcinoma, strain KB. Proc Soc Exp Biol Med 89: 362-364, 1955. 